\title{
Endovascular Management of Acute Aortic Syndromes
}

\author{
Parag J. Patel, M.D., ${ }^{1}$ William Grande, M.D., ${ }^{1}$ and Robert A. Hieb, M.D. ${ }^{1}$
}

\section{ABSTRACT}

The term "acute aortic syndrome" (AAS) refers to a spectrum of life-threatening thoracic aortic pathologies including intramural hematoma, penetrating atherosclerotic ulcer, and aortic dissection. Clinically, patients often present with characteristic aortic pain. AAS often leads to aortic rupture. Therefore, recognition of this condition, its prompt diagnosis, and timely treatment is crucial to obtain clinical success and improved overall survival. The management of AAS, however, remains a therapeutic challenge. Endovascular strategies have gained wide acceptance and now represent a minimally invasive alternative to traditional open surgery. Several studies have shown endovascular repair of varying thoracic aortic pathologies to be technically feasible with fewer complications than open surgery. In this review, the authors discuss AAS pathology and its management, with particular attention to the current role of endovascular aortic repair and its treatment.

KEYWORDS: Penetrating atherosclerotic ulcer, intramural hematoma, aortic dissection

Objectives: Upon completion of this article, the reader should be able to explain the clinical presentation and imaging findings of acute aortic dissection, penetrating atherosclerotic ulcer, and intramural hematoma, and the role for endovascular management in their treatment.

Accreditation: Tufts University School of Medicine is accredited by the Accreditation Council for Continuing Medical Education to provide continuing medical education for physicians.

Credit: Tufts University School of Medicine designates this journal-based CME activity for a maximum of 1 AMA PRA Category 1 Credit $^{\mathrm{TM}}$. Physicians should claim only the credit commensurate with the extent of their participation in the activity.

The term "acute aortic syndrome" (AAS) was first introduced into the literature in $1998^{1}$ and further characterized in 2001 by Villacosta et $\mathrm{al}^{2}$ to describe a variety of acute aortic pathologies. These include aortic dissection, intramural hematoma (IMH), and penetrating atherosclerotic ulcer (PAU).

The clinical entities that give rise to AAS are distinct with varying pathophysiologic mechanisms that precipitate their appearance and therefore distinguish their radiologic findings. However, it is clear that there is considerable overlap. Furthermore, the progression from one pathologic process to another has been documented. That is to say, some patients with IMH may evolve into an aortic dissection whereas others with PAU are accompanied by some degree of IMH; furthermore, penetrating ulcers may act as the entry site for aortic dissection. It is clear that while these acute aortic pathologies appear mostly separate, in some patients one may precede the other and often times may coexist (Fig. 1).
${ }^{1}$ Division of Vascular and Interventional Radiology, Department of Radiology, Medical College of Wisconsin, Froedtert Memorial Lutheran Hospital, Milwaukee Wisconsin.

Address for correspondence and reprint requests: Parag J. Patel, M.D., Assistant Professor of Radiology, Vascular and Interventional Radiology, Medical College of Wisconsin, Froedtert Memorial Lutheran Hospital, 9200 W Wisconsin Avenue, Milwaukee, WI
53226 (e-mail: papatel@mcw.edu).

Thoracic Interventions; Guest Editor, Charles T. Burke, M.D.

Semin Intervent Radiol 2011;28:10-23. Copyright (C) 2011 by Thieme Medical Publishers, Inc., 333 Seventh Avenue, New York, NY 10001, USA. Tel: +1(212) 584-4662.

DOI: http://dx.doi.org/10.1055/s-0031-1273936.

ISSN 0739-9529. 
A
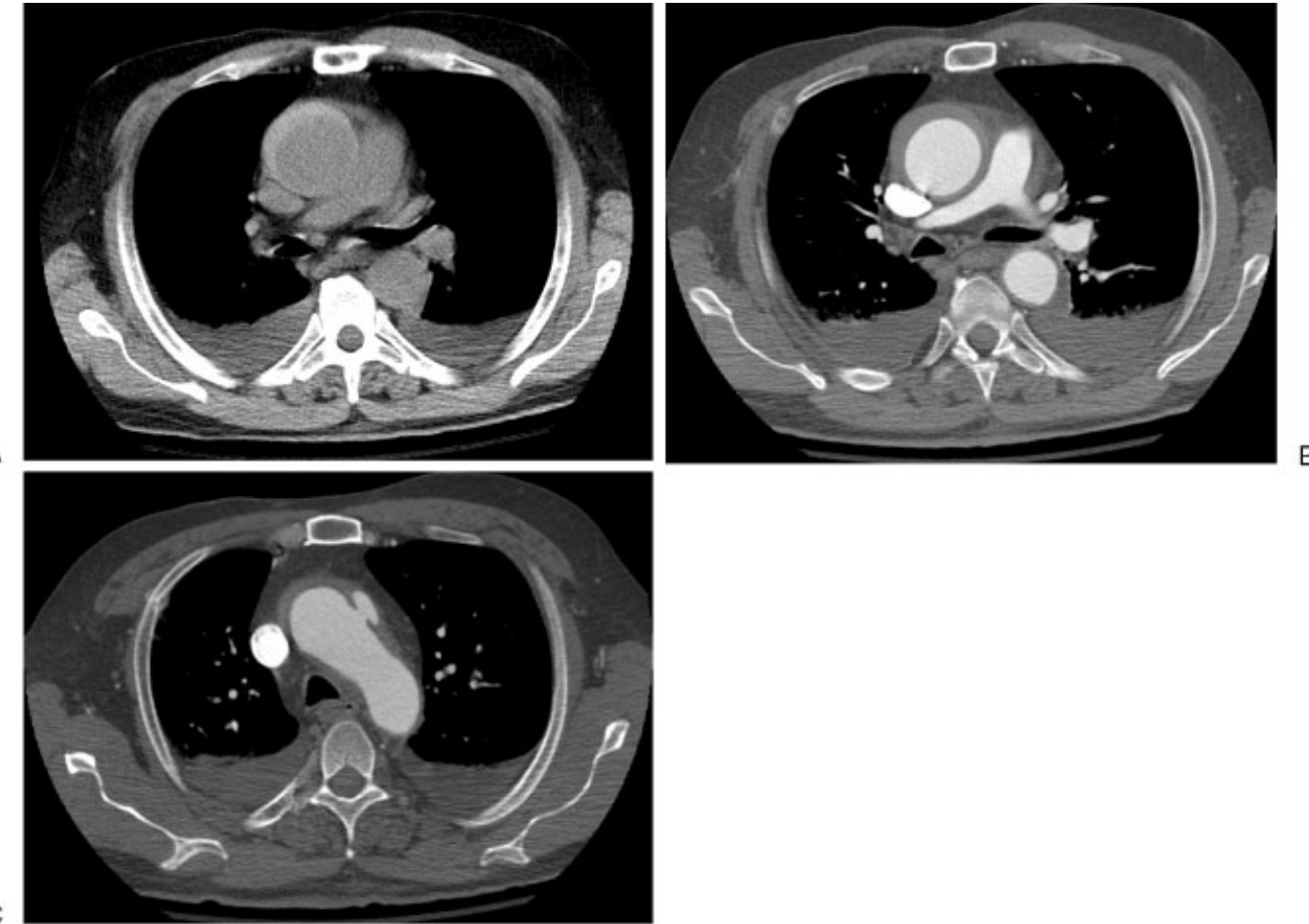

Figure 1 Type A intramural hematoma (IMH) with penetrating atherosclerotic ulcer (PAU). (A) A noncontrast axial computed tomography (CT) image of the ascending aorta demonstrates a high-attenuation crescent representing intramural hematoma. (B) Contrast-enhanced axial CT scan at the same level confirms the presence of $\mathrm{IMH}$. (C) A coexisting penetrating atherosclerotic ulcer is noted in the aortic arch.

These entities also share a common classification system. Although the Stanford Classification was originally applied to aortic dissection, it now defines AAS pathologies according to location, which broadly correlates with its management. By definition, type A pathologies affect the ascending aorta and aortic arch and type $B$ pathologies affect the descending aorta defined as those distal to the origin of the left subclavian artery.

AAS is characterized by "aortic pain" and a history of underlying severe hypertension is frequently present. Aortic pain has been described as a severe, sudden onset of tearing or ripping migratory chest pain. Chest pain that radiates to the neck, throat, or jaw typically indicates the aortic segment involved is the ascending aorta; pain located in the back or abdomen suggests involvement of the descending aorta. Additional diagnostic clues may be the presence of a murmur of aortic regurgitation and pulse differentials.

The need to consider and promptly diagnose acute chest pain or acute thoracic pathology as an AAS is clear. Although AAS has a relatively lower annual incidence compared with acute coronary syndrome $(0.5$ vs 3.0 per 100,000), AAS has an inordinately high rate of mortality. ${ }^{3}$ In fact, AAS is the most frequently fatal condition in the spectrum of patients with chest pain. ${ }^{4}$ Therefore, though acute myocardial infarction must be excluded, other clinical entities such as AAS should be considered. Furthermore, with the aging population and improved imaging techniques at our disposal, this entity is becoming a more commonly encountered clinical phenomenon.

The advent of improved endovascular techniques and devices has facilitated recent advances in the management of thoracic aortic pathology. Many of the patients who are at risk for developing AAS are poor surgical candidates and conservative medical management alone is often inadequate. Minimally invasive alternatives such as endovascular thoracic aortic repair are increasingly being undertaken. The aim of this review is to provide an overview of AAS pathology, its management, and in particular to assess the current role of endovascular thoracic aortic repair in its treatment.

\section{PATHOLOGY}

Aortic dissection is characterized by the existence of an intimomedial entrance tear, and in the majority of cases, a reentrance tear. Intramural hematoma is characterized by the presence of a hemorrhage into the aortic media, which leads to the development of a false lumen. The entrance and reentrance tears seen in classic aortic dissection are absent. Aortic ulcers usually penetrate through the intima into the media. A causal relation has been proposed linking these three conditions. The 
A
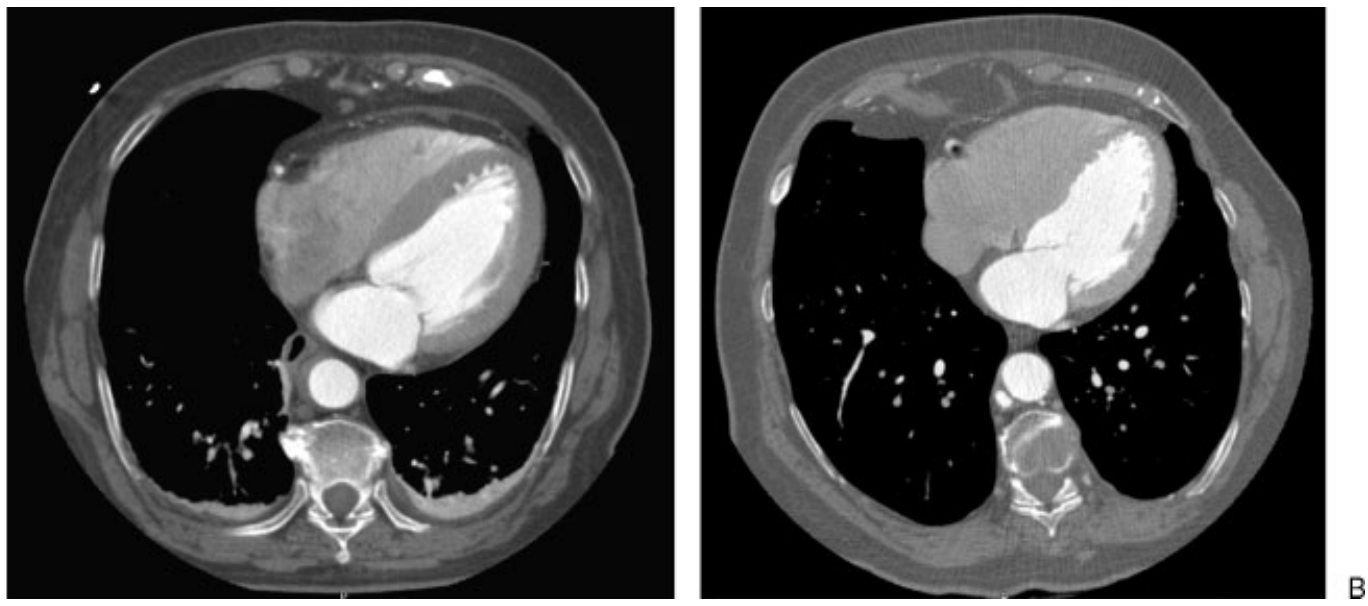

Figure 2 Type B intramural hematoma (IMH) evolves to dissection. (A) An axial computed tomography scan shows a type B $\mathrm{IMH}$. (B) Follow-up imaging 4 months later shows IMH evolution to aortic dissection.

presence of an ulcer may precipitate both an intramural hemorrhage and a classic dissection, a condition that usually occurs in a severely atherosclerotic aorta. An intramural hematoma, in turn, may precipitate a dissection (Fig. 2).

\section{Aortic Dissection}

Aortic dissection involves a tear in the intimal lining of the aorta allowing blood to flow within the layers of the media. The commonly referred to intimal flap in the aortic dissection is actually a misnomer as the tissue flap is composed mainly of aortic media that is delaminated from the aortic wall; hence, it is more appropriately referred to as an intimomedial tear. The proportion of aortic media that remains at the outer wall of the false channel differs from patient to patient. The more media involvement in the intimomedial flap, the thinner the external wall of the false lumen, and the more likely it will be to rupture. ${ }^{5}$ False channel rupture is the most common mechanism of death in patients with aortic dissection. Additionally, the false lumen may compress the true lumen (Fig. 3A-D) or extend into branch arteries creating malperfusion states. The entrance can occur at any point throughout the aorta, although is most frequently found in areas of greatest hydraulic stress such as the right lateral wall of the ascending aorta or in the proximal segment of descending thoracic aorta. Additionally, it is not uncommon for patients with aortic dissection to have a reentrance tear and several communicating points between the true and false lumen throughout the descending thoracic aorta and abdominal aorta.

It is estimated that dissections of the descending thoracic aorta occur with an incidence of 2-3.5 cases per 100,000 with up to 14,000 reported new cases in the United States each year. ${ }^{6-8}$ As previously discussed, aortic dissections are classified by location with type A pathologies involving the ascending aorta and aortic arch and type $\mathrm{B}$ pathologies involving the descending thoracic aorta. Dissections can also be classified temporally into acute and chronic phases. The acute phase is defined as $<14$ days from the onset of symptoms. This was based on early studies of aortic dissections demonstrating an increased associated mortality occurring within the first 2 weeks. ${ }^{9}$ Additionally, dissections are typically classified as complicated or uncomplicated. Complicated dissections involve those with malperfusion, rupture or impending rupture, refractory hypertension, or continued pain. ${ }^{10}$ Approximately $30 \%$ of type $\mathrm{B}$ dissections are complicated at initial presentation. ${ }^{11}$ Others have advocated stratification of uncomplicated type B dissections as those with or without high risk features. ${ }^{12}$

Patients with type A dissections in the International Registry of Aortic Dissection (IRAD) database had an overall in-hospital mortality of $27 \%$ for patients treated surgically and $56 \%$ for those treated medically. ${ }^{13}$ This underscores the current treatment paradigm where all patients with type $\mathrm{A}$ dissections undergo emergent surgical repair regardless of whether the dissection is complicated or not. Conversely, patients with type B dissection treated medically have markedly reduced early mortality in the range of $10-17 \%{ }^{3,8,14}$ The most common cause of death in these patients was rupture closely followed by symptomatic branch vessel involvement with malperfusion.

\section{Intramural Hematoma}

$\mathrm{IMH}$ is thought to be present in $10-30 \%$ of patients with AAS $^{5,15}$ IMH is considered a variant of classic aortic dissection where blood collects within the aortic media without the presence of an intimal flap (Fig. 4). ${ }^{16}$ The false lumen is created by rupture of the vasa vasorum that lies in the media or from hemorrhage within an atherosclerotic plaque. ${ }^{17}$ It is important to note that 
IMH may not only be attributed to spontaneous rupture of a "sick" vasa vasorum, but may also be the result of traumatic rupture of "healthy" vasa vasorum during blunt aortic trauma. ${ }^{5}$ Additionally, the hematoma, while often intramedial in nature, may extend through the outer medial layer into the subadventitial space representing a contained aortic rupture. Conversely, the intramedial hemorrhage may also extend toward the aortic lumen and progress to dissection. Complications of IMH are common with reported progression to complete dissec- tion in $28-47 \%$ of cases and early aneurysm formation or contained rupture in $20-45 \%$ of patients. ${ }^{18}$ However, some patients may show spontaneous resolution of IMH under medical treatment.

Predictors of disease progression and mortality include recurrent or persistent pain, the presence of a concomitant PAU, involvement of the ascending aorta and maximum aortic diameter $>50 \mathrm{~mm} \cdot{ }^{5,19,20}$ Although the aortic diameter itself is the main determinant of wall stress, IMH places increased stress on the wall of the
A

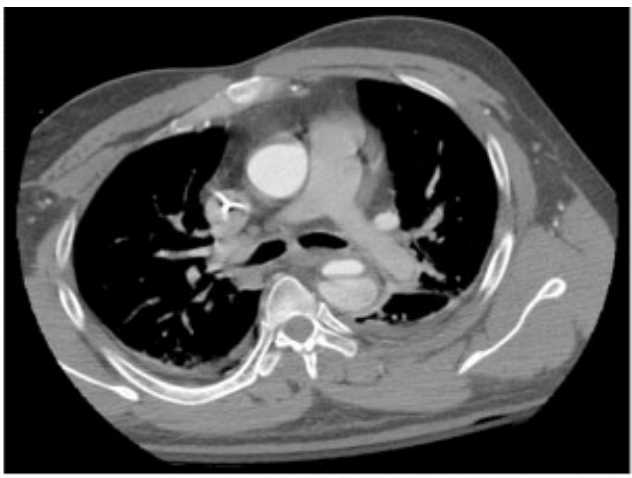

C

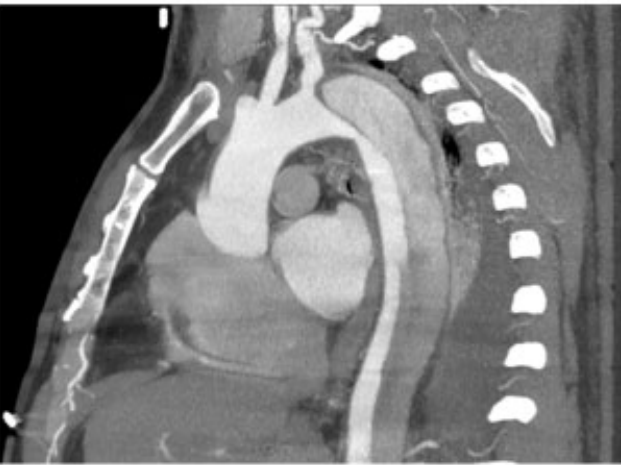

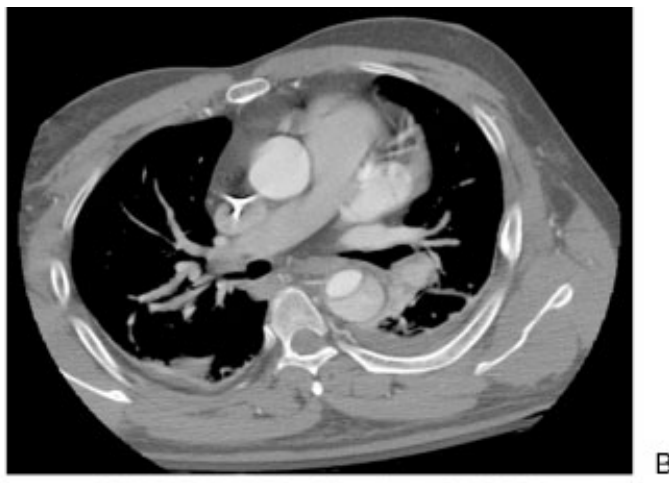
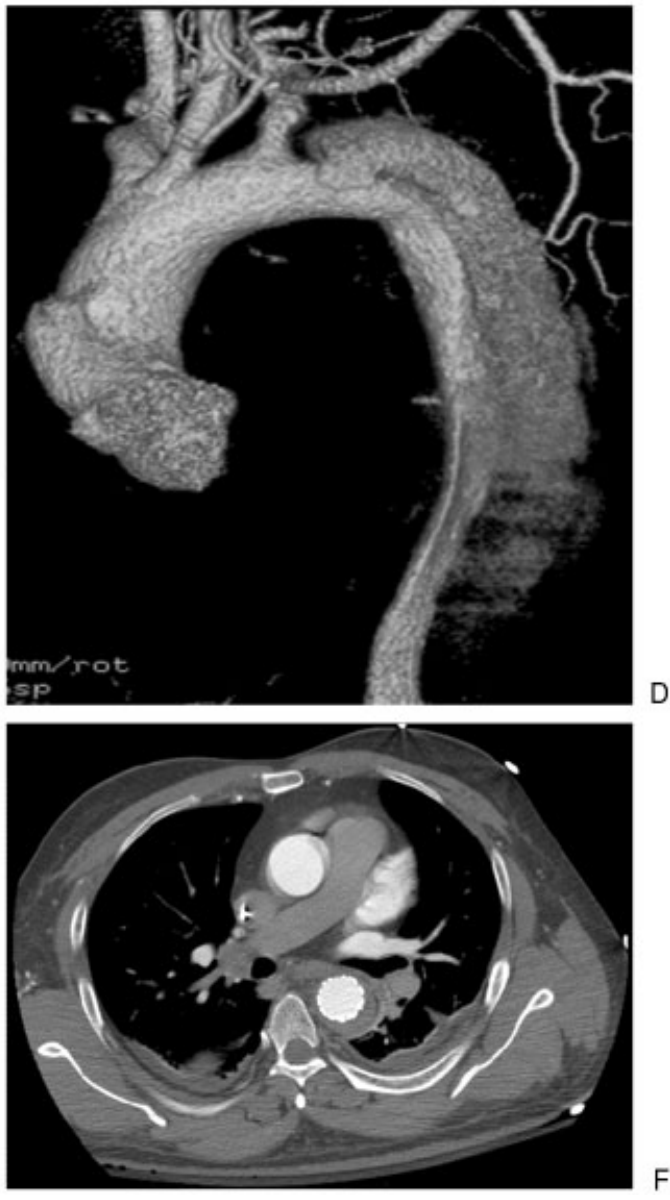

E

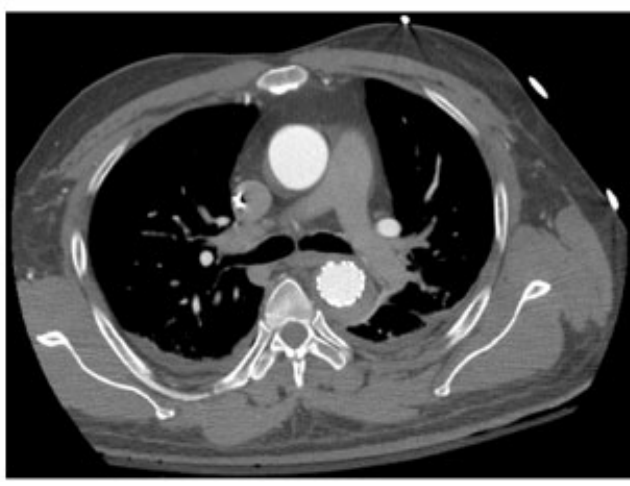

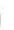

Figure 3 Type B aortic dissection treated with a thoracic stent graft with subsequent false lumen remodeling. (A,B) Select axial images $\mathrm{CT}$ at the level of the main and right pulmonary arteries shows a type B dissection with compression of the true lumen. (C,D) Sagittal oblique reformatted and volume-rendered imaging of the thoracic aorta shows the origin of the aortic dissection just distal to the left subclavian artery extending throughout the descending thoracic aorta. Marked compression of the true lumen is noted. 
G
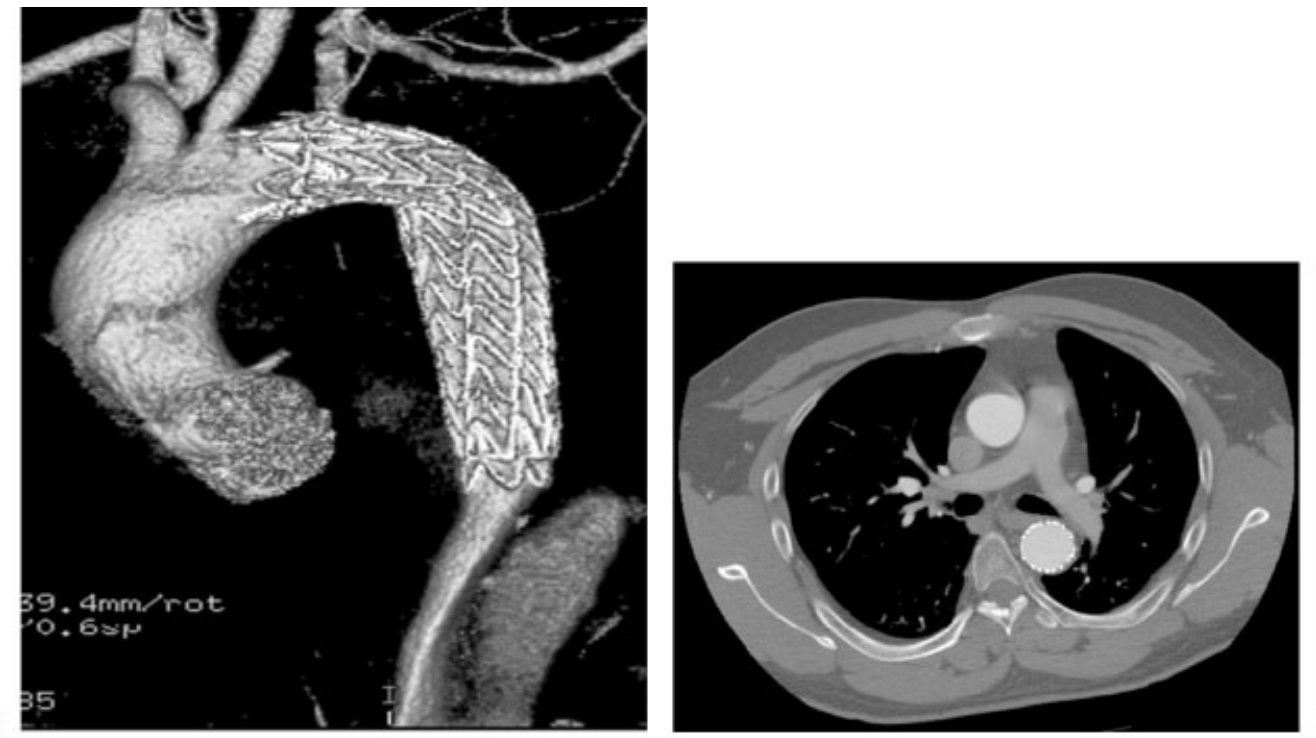

$\mathrm{H}$
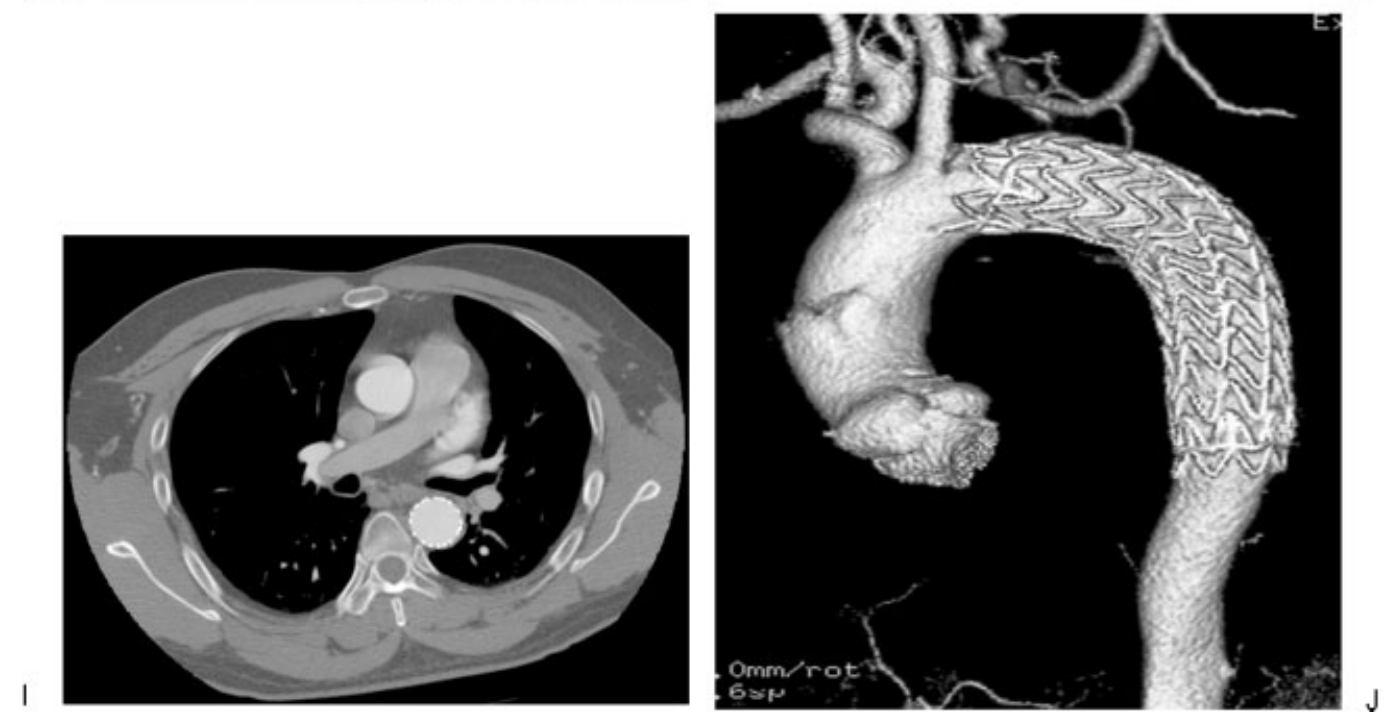

Figure 3 (Continued) (E-G) Follow-up CT imaging 5 days following thoracic stent-graft placement shows lack of false lumen blood flow at the site of primary intimomedial tear; however, false lumen flow is noted in the distal descending thoracic aorta. $(\mathrm{H}-\mathrm{J})$ Follow-up CT imaging 20 months following thoracic stent-graft placement demonstrates improved true lumen patency throughout the descending thoracic aorta with no flow and subsequent remodeling of the false lumen.

aorta. Therefore, the presence of IMH in an already dilated aorta would be expected to carry a greater risk of dissection and rupture. Predictors of resolution or improved prognosis include younger age, aortic diameters $<45 \mathrm{~mm}$, and thickness of the hematoma $<10 \mathrm{~mm}^{21,22}$

\section{Penetrating Atherosclerotic Ulcer}

PAU has been found to be in $2.3-7.6 \%$ of patients with AAS. ${ }^{1}$ PAU is defined by an ulceration of an aortic atherosclerotic plaque, which penetrates the internal elastic lamina into the aortic media. ${ }^{23}$ These patients therefore tend to be older with greater cardiovascular comorbidity. PAUs are usually focal lesions and may be found anywhere in the aorta; however, they are most commonly located in the descending thoracic aorta
(Fig. 5). This may reflect the increased presence of atheromatous disease in this location. PAUs, though focal, may be single or multiple, and the excavated "crater" of these ulcerated lesions may contain debris, cholesterol, and thrombotic material. Progressive intimal erosion can lead to blood entering the media. This may precipitate an aortic dissection or formation of IMH. Further penetration to the adventitia may lead to pseudoaneurysm formation with contained or even free rupture. ${ }^{23-26}$ Not surprisingly therefore, PAU has the highest rate of aortic rupture up to $42 \%$ when compared with IMH or aortic dissection. ${ }^{27}$ This underscores the aggressive surgical approach many groups have taken in treatment of PAU. Even so, other groups have reported success with a nonoperative expectant approach. ${ }^{28,29}$ Still, it appears that symptomatic patients presenting 
A
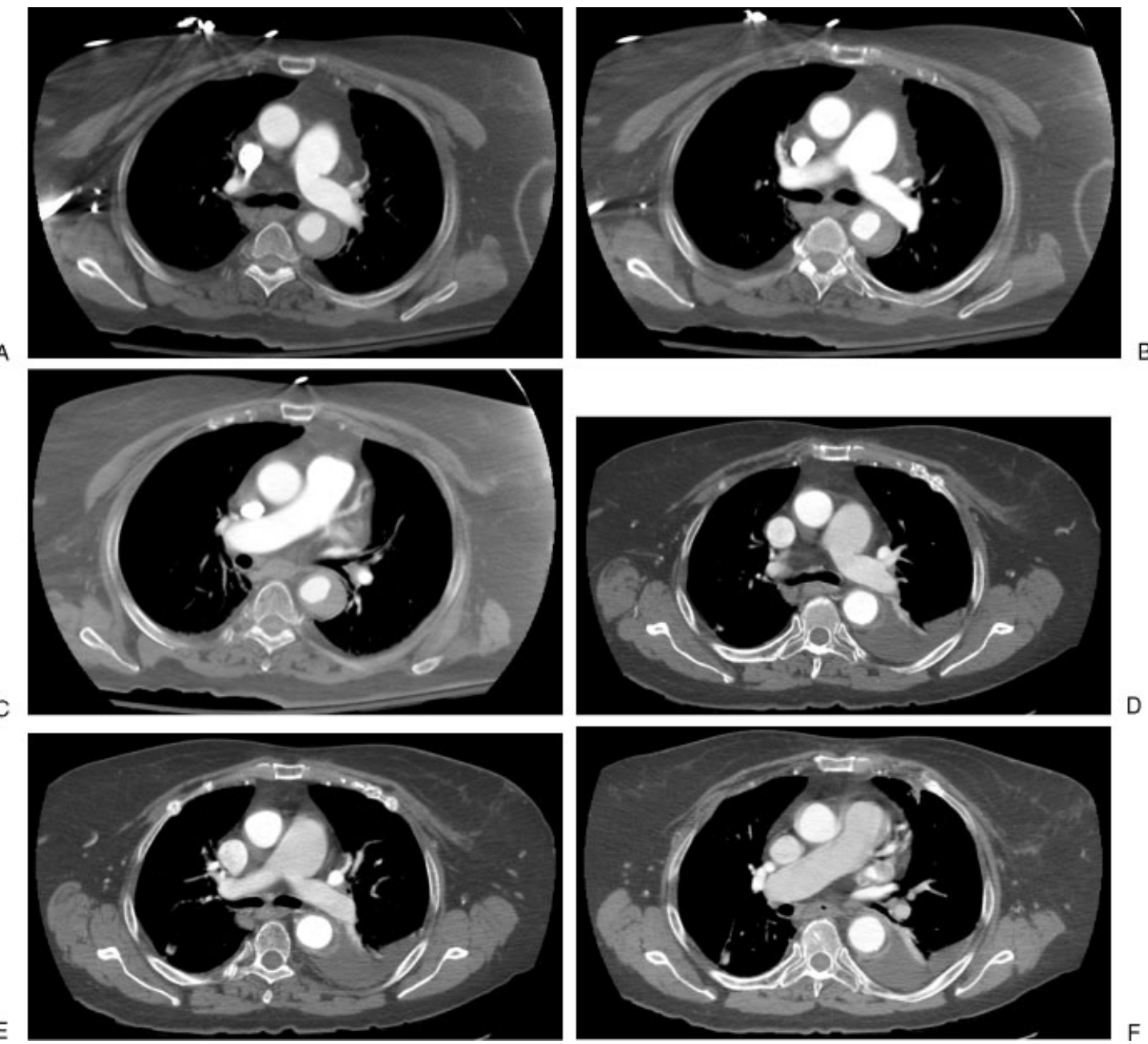

Figure 4 Type B intramural hematoma (IMH) resolving with best medical therapy. Type B IMH was found in a patient with previously untreated hypertension. (A-C) Select axial computed tomography images show a moderate-sized type B IMH. There were no complicating features and the patient was treated with best medical therapy. (D-F) Follow-up CT imaging 8 months later demonstrates residual type B IMH that has significantly improved in appearance.

with PAU have a worse prognosis than asymptomatic patients with incidentally found PAU. Additional high risk features include lesion size $\geq 20 \mathrm{~mm}$ or depth $>10 \mathrm{~mm} .{ }^{22}$ The natural history of PAUs is unknown. However, many authors have documented progression from PAU to aneurysmal dilatation, ${ }^{30}$ ulcer extension into the adventitia to form a pseudoaneurysm, ${ }^{1}$ or an entrance point to aortic dissection. ${ }^{31,32}$

\section{MEDICAL MANAGEMENT}

Medical management in patients with AAS consists of close intensive care unit monitoring with tight regulation of blood pressure, heart rate, and pain control. The overall goal is to decrease aortic wall sheer stress. General guidelines to achieve this goal include a heart rate $<60$ beats per minute and systolic blood pressure $<100$ $120 \mathrm{~mm} \mathrm{Hg}$ or mean arterial pressure $<60-76 \mathrm{~mm}$ $\mathrm{Hg}$. Beta blockers are a staple of optimal medical management. However, additional hypertensive agents are also often required. Regardless of dissection location, all patients in whom there is a strong suspicion of aortic dissection should be immediately placed on antihypertensive therapy to limit progression of dissection. ${ }^{33,34}$

The concept of antiimpulse pharmacologic management is the mainstay of medical therapy in patients with AAS. However, the ideal medical management following initial discharge is not as well defined. It would seem that following the same antiimpulse regimen used to treat patients acutely would have continued long-term benefit. Several reports advocate the use of $\beta$ blockers, ${ }^{35}$ tight heart rate control, ${ }^{36}$ and alternative antihypertensive agents such as angiotensin converting enzyme inhibitors. ${ }^{37}$ Although $\beta$ blockade and tight heart rate control help diminish overall aortic wall sheer stress, there is evidence that angiotensin converting enzyme inhibitors have unique vascular remodeling properties. ${ }^{38}$ Finally, it is important to note that because medical therapy alone does not stop blood flow to the false lumen, a significant number of patients who survive 
A
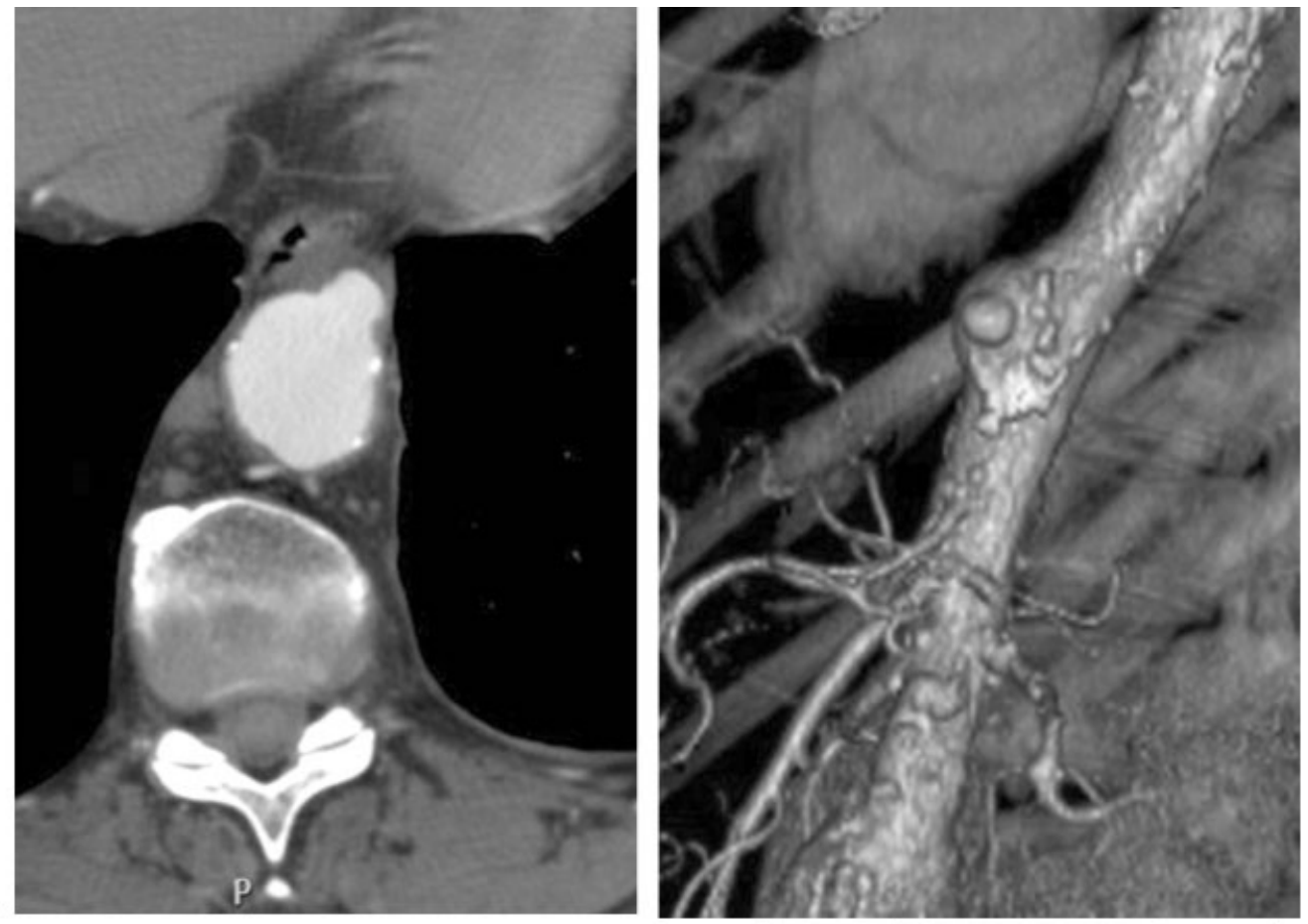

B
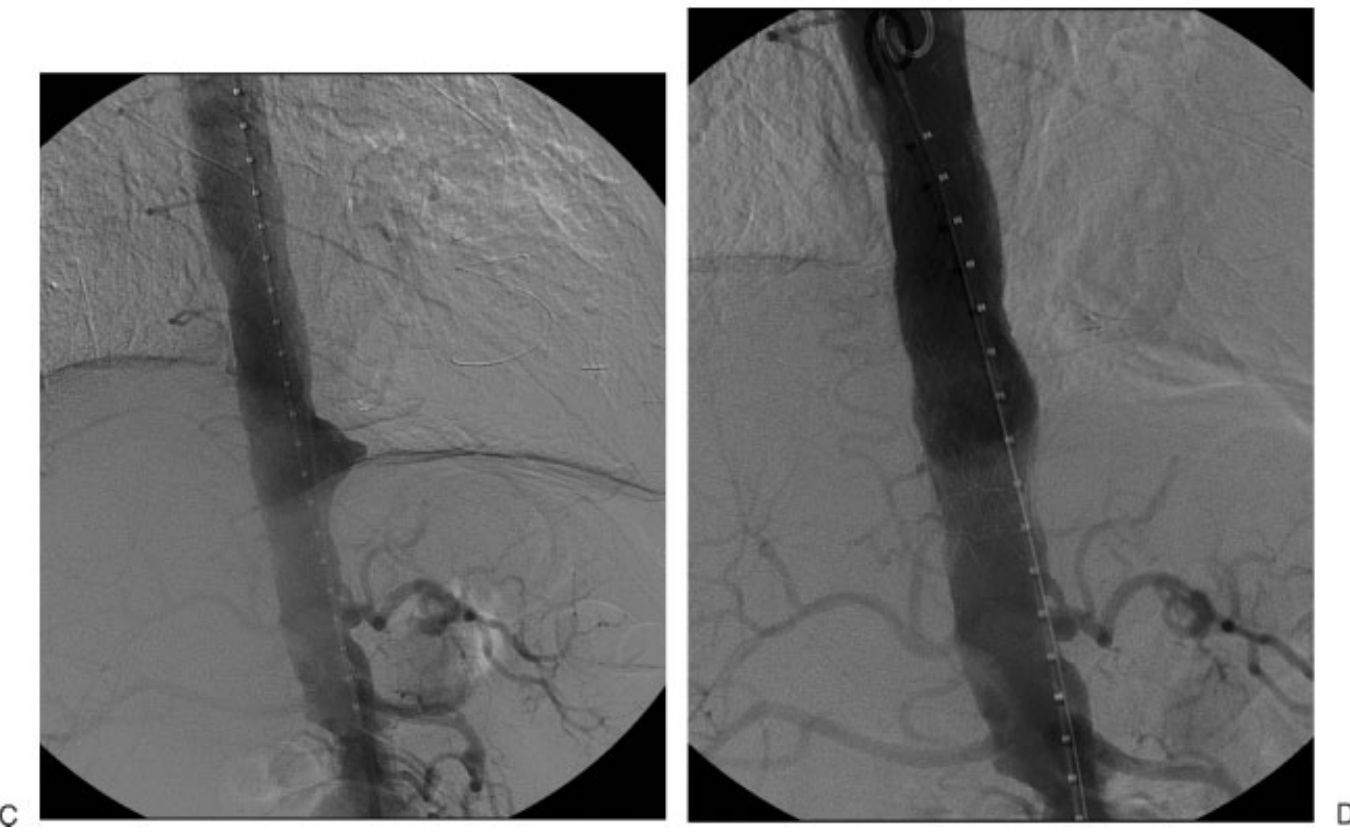

Figure 5 Type B penetrating atherosclerotic ulcer (PAU) treated with thoracic stent graft. (A) Axial computed tomography (CT) image shows a penetrating ulcer in the descending thoracic aorta. (B) Volume-rendered imaging demonstrates the focal nature of this disease in the distal descending thoracic aorta. (C) Angiographic image of the PAU during planned endovascular treatment. (D) Postendograft placement angiography shows successful exclusion of previously shown distal type B PAU.

the acute phase develop late aneurysmal degeneration of the false lumen in $1-5$ years. ${ }^{39,40}$

\section{SURGICAL MANAGEMENT}

A discussion of potential endovascular treatments of AAS would not be appropriate without a brief discussion of the current surgical management. This highlights opportunities for improved morbidity and mortality and places proper context for the role of our newer less invasive treatment alternatives.

\section{Aortic Dissection}

The treatment paradigm for aortic dissections dates back to the work in the late 1960s and early 1970s 
demonstrating the disparate outcomes between dissections involving the ascending aorta and those isolated to the descending thoracic aorta. ${ }^{38}$ The standard management of type $\mathrm{A}$ aortic dissections since that time has been surgical repair of the ascending aorta with additional repair of the aortic arch, aortic root, or aortic valve as necessary. ${ }^{41}$ Traditionally, operative repair of type A aortic dissections has been limited to the ascending aorta. More recently, endovascular techniques have been added as adjuncts to the surgical management of type A dissections. For dissections extending into the descending thoracic aorta, placement of a stent graft into the unrepaired descending aorta can reduce the complications related to the residual dissected vessel. ${ }^{42,43}$ Others have advocated endovascular treatment of type A dissections that extend in a retrograde fashion (the so-called retro-A dissection) from a dissection originating in the descending thoracic aorta by covering the primary entry site tear. Additionally, some groups propose endovascular treatment of malperfusion states in patients with type A dissections before operative repair of the ascending aorta. ${ }^{44,45}$ Branched endografts may allow for endovascular repair of classic type A dissections in the future, but no suitable devices are currently available.

Given the low in-hospital mortality rates for uncomplicated type B dissections managed medically, early surgical repair has generally been reserved for patients with complicated type B dissections. A type B dissection is considered complicated when there is rupture or impending rupture, pain or hypertension refractory to medical therapy, progression of the dissection despite optimal medical therapy, and visceral or limb ischemia. Surgical repair is also indicated in cases of aneurysmal degeneration of the dissected segments of the descending aorta to prevent late aortic rupture. Surgical repair for aneurysmal disease usually involves a left posterolateral thoracotomy with retroperitoneal exposure of the abdominal aorta if necessary to replace the entire length of dilated aorta. Reimplantation of intercostal or lumbar arteries can be performed if necessary during an open surgical procedure. Surgical fenestration can be performed if the entire dissected segment of the aorta is not removed. ${ }^{46}$ Surgical treatments of malperfusion states include surgical bypass of the ischemic vascular beds as well as surgical fenestration. However, mortality rates for operative repair in the setting of complicated type B dissections remain high. ${ }^{11,47}$

\section{Intramural Hematoma}

In general, the surgical treatment of IMH parallels the treatment of aortic dissection. However, given the less well-established natural history of IMH, optimal surgical management remains a matter of debate. Consensus favors operative repair of type $\mathrm{A}$ intramural hematoma with excision of the affected segment and replacement with a surgical graft. However, rates of surgical repair for type A IMH are lower than the corresponding rates for type A dissections. Surgical treatment for type B IMH is usually reserved for aneurysmal degeneration of the aorta, persistent pain or hypertension, or organ/limb ischemia. Additional high risk features that may indicate treatment of IMH include an aortic diameter $>50 \mathrm{~mm}$, a hematoma thickness $>11 \mathrm{~mm}$, or pleural/pericardial fluid. The surgical techniques employed for repair of IMH parallel those for aortic dissections described above. ${ }^{18,21,48-50}$

\section{Penetrating Atherosclerotic Ulcer}

Similar to IMH, the optimal treatment of PAUs remains a matter of debate given its lower prevalence and less well-understood natural history compared with traditional aortic dissection. Some series have reported rates of rupture as high as $38 \%{ }^{51}$; others have described more successful management of PAUs with medical management as compared with surgical therapy. High risk features include lesion size of $\geq 20 \mathrm{~mm}$ or depth $>10 \mathrm{~mm} .{ }^{22}$ When operative repair is required, graft replacement of the entire involved aorta is performed. It is of particular importance to remove the aortic segment including the PAU in the setting of concomitant dissection or intramural hematoma. ${ }^{21}$

\section{ENDOVASCULAR MANAGEMENT}

The introduction of endovascular techniques for the treatment of acute aortic syndromes has the potential to significantly alter the risk/benefit ratios for medical therapy versus repair. Although no prospective randomized trials comparing endovascular techniques to surgical therapy have been conducted, multiple reports have demonstrated high technical success rates and low rates of morbidity and mortality with endovascular techniques employed to treat acute aortic syndromes. ${ }^{52}$

\section{Aortic Dissection}

Options available to the interventionalist treating aortic dissections include branch vessel stenting, aortic fenestration, aortic endograft placement, or a combination of these techniques. Selection of the appropriate treatment method is based on the indication for the intervention, dissection anatomy, and flow dynamics within the true and false lumens. Of immediate concern in treating complicated aortic dissection is revascularization of ischemic vascular beds in malperfusion syndromes. Branch vessel obstruction can be related to either static or dynamic obstructions, as classified by Williams et al..$^{53}$ Static obstruction refers to propagation of the dissection 
or associated thrombus into the branch vessel itself, with restriction of flow through the perfusing lumen. Dynamic obstruction refers to intermittent obstruction of a branch vessel origin by the aortic dissection flap itself, as well as to obstruction of one aortic lumen (usually the true lumen) by the other lumen above a branch vessel origin. An additional goal in the treatment of aortic dissection includes protecting the patient from further aortic-related complications such as delayed rupture or aneurysm formation.

\section{FENESTRATION}

The goal of endovascular aortic fenestration is to treat malperfusion syndromes by equalization of pressures between the true and false lumens, relieving the dynamic aortic component of obstruction caused by the dissection. In some cases, adjunctive aortic stenting may be used to maintain expansion of the true lumen. Branch vessel stenting is then used to treat the static obstruction of branch vessels caused by the dissection. These techniques are thus widely applicable in treating malperfusion symptoms caused by both static and dynamic obstructions, and can be applied no matter the location of the primary tear. However, application of fenestration and branch stenting techniques is time consuming, technically demanding, and often requires complex intraprocedural decision making. Additionally, in preserving flow through the false lumen the fenestration procedure does not address other potential complications of the dissection, namely aneurysm formation and late rupture.

Static obstruction caused by extension of the dissection flap or hematoma into branch vessels is treated with placement of stents within the branch vessel from the perfusing lumen. Branch vessel stenting should be performed after treatment of dynamic aortic obstruction (either by fenestration or stent graft placement) if the two conditions coexist to optimize vessel inflow. Superior mesenteric obstructions should be treated before renal or iliac lesions, given the bowels decreased tolerance for ischemia compared with the kidney or lower extremities. Extension of the trailing stent edge further into the aortic lumen than used for treatment of ostial atherosclerotic lesions is advocated. ${ }^{53}$ The aorta should be reassessed after treatment of large branch vessel obstructions, as improving outflow from one lumen can alter the flow dynamics to such a degree that a new dynamic obstruction within the aorta can occur. Some authors have advocated preferentially using the false lumen as the inflow for an ischemic vascular bed with branch vessel obstruction to avoid such a result. ${ }^{47}$

\section{STENT GRAFTS}

Thoracic stent grafts were first utilized for the repair of aortic dissections slightly over a decade ago. Treatment with covered stents is primarily aimed at sealing a primary tear within the thoracic aorta, decreasing flow through the tear into the false lumen and directing blood flow preferentially through the true lumen (Fig. 3H-J). The redirection of blood flow to the true lumen often relieves downstream dynamic obstructions. As opposed to fenestration, however, stent grafting can also lead to thrombosis and remodeling of the false lumen, which may decrease the risk of subsequent aortic rupture or late aneurysmal dilatation. ${ }^{52}$

Stent grafts deployed for the treatment of aortic dissections should extend $20-40 \mathrm{~mm}$ beyond the primary intimal tear site in both the proximal and distal directions. Distal aortic tears are left uncovered and allowed to remain open for several reasons. First, the small tears will allow for continued perfusion of branch vessels supplied by the false lumen. Second, these distal tears are usually of sufficiently small size that they do not allow sufficient pressurization for true lumen obstruction or aortic rupture. Third, minimizing initial overall graft length decreases risk of paraplegia; if thrombosis of the false lumen does not occur additional graft segments can be inserted at a later time. ${ }^{48,54-56}$

Stent graft placement can be limited in certain individuals by excessive aortic tortuosity, intramural thrombus, or calcification. Additionally, small femoral or iliac vessels can limit the use of aortic stent grafts in some patients. Another consideration is the location of the proximal landing zone. If the primary intimal tear is within $20 \mathrm{~mm}$ of the left subclavian artery origin, coverage of the origin by the stent graft may be necessary to ensure an adequate seal (Fig. 3G). The contralateral subclavian and vertebral arteries as well as the circle of Willis should be studied. Selective revascularization of the left subclavian artery when there is an incomplete circle of Willis or if the left vertebral artery is dominant has been advocated rather than universal revascularization, especially considering the urgent/emergent need for the aortic repair.

No prospective trial evaluating outcomes of patients with complicated dissections treated with open surgery versus endovascular repair has been or will likely be performed. However, retrospective analysis of patients within the IRAD registry undergoing endovascular or open repair of complicated type B dissections demonstrated lower in-hospital mortality (10.6\% vs $33.9 \%)$ and neurologic/ischemic composite morbidity (20.8\% vs $40.0 \%$ ) in the endovascular group as compared with the open surgical cohort. ${ }^{11}$ Given the paucity of long-term data, particularly regarding the use of endografts in acute aortic syndromes, caution is urged in employing endovascular treatment methods in young patients who are otherwise good operative candidates. Similarly, patients with connective tissue disorders may be unsuitable for endograft repair given the diffuse abnormality of their vasculature, with 
increased predisposition to further dissection and aneurysmal dilation. ${ }^{43}$

In addition, no trial comparing outcomes of complicated type B dissections treated with stent-graft procedures and fenestration has been performed. However, stent-graft procedures have gained popularity, likely in part due to the relative simplicity and speed of the procedure compared with fenestration, as well as increased familiarity with the techniques and devices used in their applications for treating aneurysmal disease. Though head-to-head comparisons are lacking, hemodynamic models suggest that decreasing flow into the false lumen is more effective in treating malperfusion states compared with fenestration. ${ }^{47}$ Analysis of complicated type B dissections from the IRAD database reveals that malperfusion states were relieved in 9 of 18 patients treated with endovascular fenestration and 16 of 17 patients treated with stent graft. ${ }^{11}$ Given the theoretical advantages of stent graft therapy, DiMusto et al suggested an algorithm for treatment of aortic dissections in which endograft therapy was used if a suitable entry tear was present, with fenestration reserved for cases where malperfusion is present and there is no entry tear amenable to endograft treatment. ${ }^{52}$

Endovascular repair in addition to medical therapy is now accepted for the treatment of complicated type B aortic dissections. Uncertainty exists over the use of endovascular techniques in the treatment of uncomplicated acute aortic syndromes of the descending thoracic aorta. The risk/benefit profile has favored medical management of uncomplicated type B intramural hematomas and dissections compared with open surgical therapy. Yet rates of late aortic complications between 25-50\% have been reported in patients treated with medical therapy alone. ${ }^{38}$ It has been hypothesized that given the lower morbidity and mortality of endovascular repair, treatment of even uncomplicated dissections in the hope of reducing late aortic complications may be warranted. The INSTEAD (Investigation of Stent Grafts in Aortic Dissection) trial was designed to answer the question of whether aortic stent grafting in patients with subacute or chronic ( $>2$ weeks from index dissection) uncomplicated type $\mathrm{B}$ dissections could reduce late aortic related morbidity and mortality. ${ }^{57}$ Patients were randomized to optimal medical therapy versus optimal medical therapy plus endovascular treatment of the proximal aortic tear with a Talent ${ }^{\mathrm{TM}}$ stent graft (Medtronic Inc, Santa Rosa, CA). Patients treated with optimal medical therapy had overall and aortic-related death rates of $4.4 \%$ and $2.9 \%$ respectively, while the rates in the interventional group were 11.1 and $5.6 \%$. The authors noted a lower than expected mortality rate among the optimal medical therapy group. However, significant aortic remodeling was noted in the intervention group, with $91 \%$ complete thrombosis at 2 years as compared with $19 \%$ in the optimal medical therapy group $(P<0.001)$.

Although endovascular intervention failed to improve late outcomes compared with medical therapy in uncomplicated chronic type B dissections, results may differ in acute uncomplicated type B dissections. The dissection flap becomes thickened and develops an increasing number of fenestrations with time, decreasing the likelihood of thrombosis of the false lumen as a result of endograft coverage of the primary dissection tear. ${ }^{43}$ One small case series showed increased success rates in endovascular treatment of acute dissections compared with chronic dissections. ${ }^{58}$ However, a recent metaanalysis demonstrated a higher complication and mortality rate after thoracic endovascular aortic repair (TEVAR) in acute dissections compared with chronic dissections. ${ }^{59}$ More definitive data on the role of endograft therapy for acute uncomplicated aortic dissections will be forthcoming as results from the ADSORB (European Study of Medical Management Versus TAG Device and Medical Management for Acute Uncomplicated Type B Dissection) trial become available. This randomized trial will compare best medical therapy to best medical therapy plus implantation of a GORE ${ }^{\circledR}$ $\mathrm{TAG}^{\circledR}$ endograft in patients with acute $(<2$ weeks of symptoms) uncomplicated (no evidence of malperfusion) type B dissections. Enrollment for this trial began in August 2008 and the study completion date is listed as December 2012. ${ }^{60}$

Stratification of patients into type A versus type B, acute versus chronic, and complicated versus uncomplicated alone may not be sufficient to determine appropriate candidates for endovascular treatments. Recently, studies have demonstrated potential high risk features of uncomplicated type B dissections that may portend an increased risk of aneurysmal degeneration. Song et al studied 100 consecutive patients with aortic dissections. Forty-nine of these had type $\mathrm{B}$ dissections with mean computed tomography $(\mathrm{CT})$ follow-up of 3 months. Twenty-eight percent of these patients developed aneurysmal degeneration $(>6 \mathrm{~cm})$. However, the overall initial aortic diameter was not an independent predictor of eventual aneurysmal dilatation. Interestingly, the false lumen diameter measured at the upper descending aorta was highly predictive. Those patients with a false lumen diameter of $>22 \mathrm{~mm}$ were at significantly higher risk for aneurysmal formation $(42 \%$ vs $5 \%, P<0.001)$. This would suggest that patients with type $\mathrm{B}$ dissections, who are otherwise uncomplicated but have increased false lumen diameter, may represent a subset of patients in which early endovascular management may be appropriate. ${ }^{12}$

\section{Intramural Hematoma}

Several factors make endovascular stent grafting particularly well suited to the treatment of IMH. Patients who 
present with IMH tend to be older and have more significant medical comorbidities than their counterparts presenting with traditional dissections. Additionally, the more focal nature of IMH compared with dissection allows for coverage of the entirety of the abnormal aorta in a higher percentage of case. ${ }^{56}$

Two separate mechanisms have been postulated for IMH: rupture of the vasa vasorum leading to hemorrhage within the media, and extension of hemorrhage into the aortic wall from small atherosclerotic ulcers or intimal tears often located near the ligamentum arteriosum/distal arch. In cases associated with an intimal tear, the intramural hemorrhage can extend within the aorta in an antegrade or retrograde fashion. Some authors advise treating only IMH related to intimal tears in an endovascular fashion. Not surprisingly, these authors advocate using the shortest graft possible to safely cover the entry tear $(100-170 \mathrm{~mm})$ therefore, minimizing the risk of paraplegia. ${ }^{61}$ The mechanism of IMH formation has been used as a rationale by some to treat type A IMH with intimal tears within the descending aorta with descending thoracic endografts rather than the more conventional ascending aorta/arch replacement, though data for this treatment paradigm is limited. ${ }^{62}$ Other groups do not differentiate among the causes of IMH in patient selection, but advocate treatment of a longer segment of aorta $(200-250 \mathrm{~mm})$ to cover as much abnormal vessel as possible with the goal of preventing late complications by reducing wall stress. ${ }^{22}$

\section{Penetrating Atherosclerotic Ulcer}

Similar to IMH, PAU usually affects a more focal region of the aorta compared with aortic dissection. The age of patients at presentation tends to be older than either dissection or IMH, and patients tend to have more diffuse and severe atherosclerotic disease than in the other entities. Again, these factors make endovascular treatment options preferable to open surgery given the less invasive nature of the initial procedure and the increased inherent risks for open surgery in this population. $^{22}$

Given the focal nature of the abnormality in PAU, a single short stent graft can often be used to completely exclude the lesion (Fig. 5). Given the increased severity of atherosclerosis in PAU patients, the risk of a procedure-related access site or atheroembolic complications is higher as compared in patients with dissection or IMH. Therefore, minimal manipulation of the guidewire or delivery system in the arch is imperative. Additionally, consideration should be given to preferential access of the iliac arteries or the aorta from a retroperitoneal approach if the femoral arteries are diminutive or excessively diseased. $22,63,64$
Data regarding the success of endografting in the treatment of PAU is mostly limited to single-center small case series. The available data were summarized by Eggebrecht et al in 2009, who reported high overall technical success rates (98\%), and low rates of in-hospital mortality (7\%), neurologic complications (4\%), secondary procedures (5\%), and subsequent aorta-related mortality $(2 \%){ }^{22}$

\section{CONCLUSION}

The optimal treatment of patients with AAS remains a challenging clinical dilemma. It is imperative to appreciate the spectrum of clinical, anatomic, and temporal manifestations within the pathology of AAS. Previous treatment algorithms stratify thoracic aortic pathologies strictly as type A versus type B. Subsequent management was dictated based on this classification with emergent surgical management indicated for type A pathologies and best medical therapy mandated for type B pathologies. The advent of minimally invasive endovascular techniques has the potential to shift the current treatment paradigm with treatment no longer limited to best medical therapy versus surgical repair alone. The current challenge is to determine the patient population best suited for endovascular treatment rather than best medical therapy alone. In some instances, endovascular management may replace surgical repair. In contrast to uncomplicated acute type A pathologies, uncomplicated type B pathologies have a relatively favorable early prognosis without surgical intervention: the rate of complication with surgery is markedly increased when compared with medical management alone. However, it is clear that procedural morbidity and mortality is reduced with endovascular repair when compared with surgical repair. Conversely, patients with complicated type B pathologies have a very high likelihood of mortality and require emergent surgical or endovascular treatment.

It is important to note that although endovascular treatments have demonstrated improved morbidity and mortality compared with surgical treatments, they are not without risk of significant complication. The most significant of which is paraplegia. The relative occurrence of this catastrophic event appears to be less common with endovascular repair versus surgical repair and chronic versus acute pathologies. We have proposed a potential treatment algorithm for AAS in the acute setting with consideration made for disease location and the presence of complicating or high risk features (Fig. 6). Further studies will help clarify the role for minimally invasive treatments while continued refinement of these endovascular devices will only continue to improve the procedural success. 


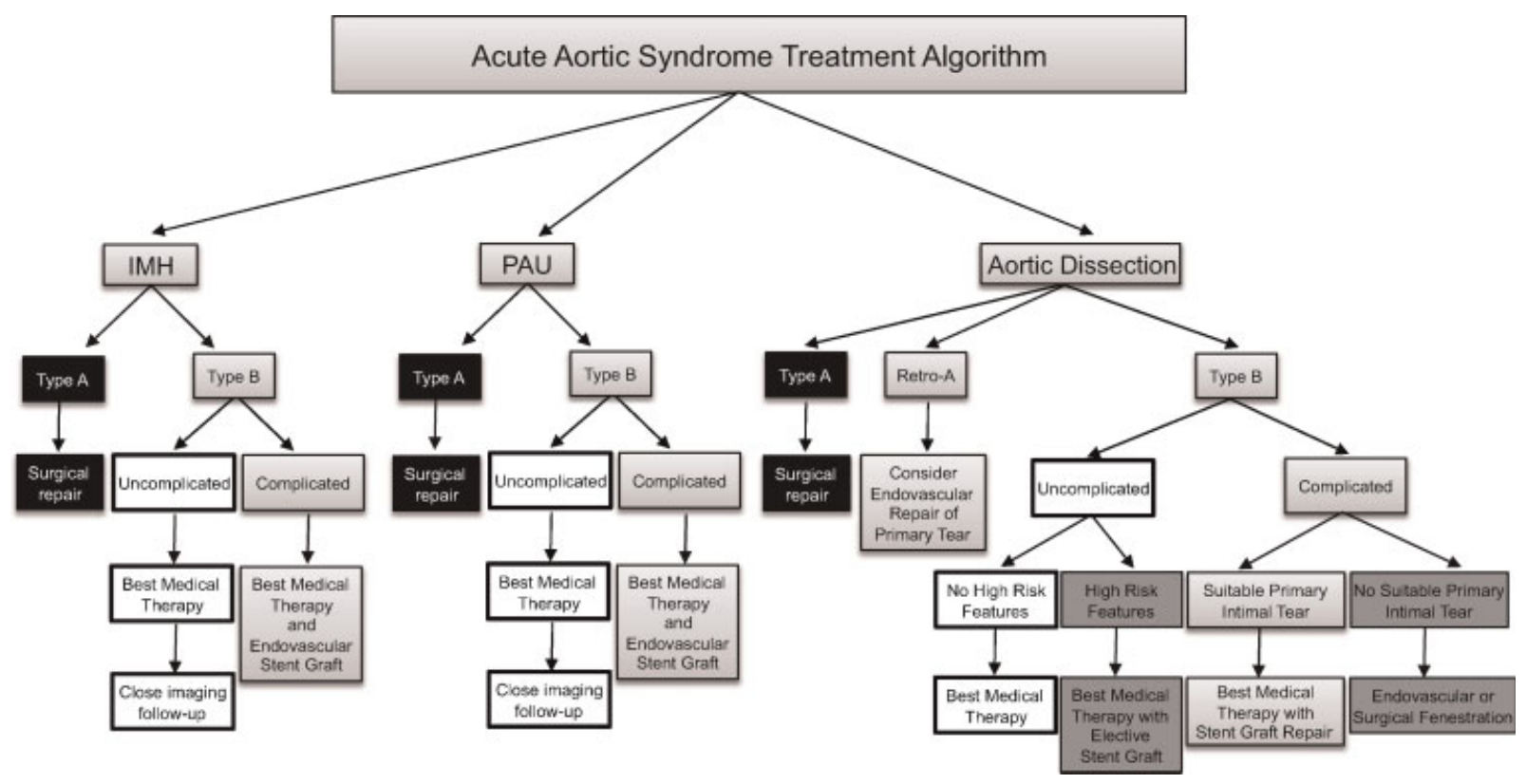

Figure 6 Proposed algorithm for the treatment of acute aortic syndrome. Best medical therapy: close intensive care unit monitoring, target systolic blood pressure (SBP) 100-120 mm Hg, beta blockade if permissible, heart rate (HR) $<60$, and pain adequately controlled. High risk features of aortic dissection: false lumen $>22 \mathrm{~mm}$ at aortic isthmus on initial presentation imaging. Retrograde type A ("Retro-A") dissection: a dissection arising from a primary tear in the descending thoracic aorta with retrograde extension into the aortic arch. Complicating features in acute aortic syndrome (AAS): pain or hypertension refractory to medical therapy, rupture or impending rupture, visceral or limb ischemia. Initial short-interval and subsequent regular followup imaging is indicated in all patients with AAS who are treated medically and with endovascular therapies. IMH,Intramural hematoma; PAU, penetrating atherosclerotic ulcer

\section{REFERENCES}

1. Vilacosta I, San Román JA, Aragoncillo P, et al. Penetrating atherosclerotic aortic ulcer: documentation by transesophageal echocardiography. J Am Coll Cardiol 1998;32(1):83-89

2. Vilacosta I, Román JA. Acute aortic syndrome. Heart 2001; 85(4):365-368

3. Hagan PG, Nienaber CA, Isselbacher EM, et al. The International Registry of Acute Aortic Dissection (IRAD): new insights into an old disease. JAMA 2000;283(7):897903

4. Kouchoukos NT, Dougenis D. Surgery of the thoracic aorta. N Engl J Med 1997;336(26):1876-1888

5. Vilacosta I, Aragoncillo P, Cañadas V, San Román JA, Ferreirós J, Rodríguez E. Acute aortic syndrome: a new look at an old conundrum. Heart 2009;95(14):1130-1139

6. Hiratzka LF, Bakris GL, Beckman JA, et al; American College of Cardiology Foundation/American Heart Association Task Force on Practice Guidelines; American Association for Thoracic Surgery; American College of Radiology; American Stroke Association; Society of Cardiovascular Anesthesiologists; Society for Cardiovascular Angiography and Interventions; Society of Interventional Radiology; Society of Thoracic Surgeons; Society for Vascular Medicine. $2010 \mathrm{ACCF} / \mathrm{AHA} / \mathrm{AATS} / \mathrm{ACR} / \mathrm{ASA} / \mathrm{SCA} / \mathrm{SCAI} / \mathrm{SIR} /$ STS/SVM guidelines for the diagnosis and management of patients with Thoracic Aortic Disease: a report of the American College of Cardiology Foundation/American Heart Association Task Force on Practice Guidelines,
American Association for Thoracic Surgery, American College of Radiology, American Stroke Association, Society of Cardiovascular Anesthesiologists, Society for Cardiovascular Angiography and Interventions, Society of Interventional Radiology, Society of Thoracic Surgeons, and Society for Vascular Medicine. Circulation 2010;121(13):e266e369

7. Song TK, Donayre CE, Walot I, et al. Endograft exclusion of acute and chronic descending thoracic aortic dissections. J Vasc Surg 2006;43(2):247-258

8. Glower DD, Fann JI, Speier RH, et al. Comparison of medical and surgical therapy for uncomplicated descending aortic dissection. Circulation 1990;82(5, Suppl):IV39-IV46

9. Crawford ES. The diagnosis and management of aortic dissection. JAMA 1990;264(19):2537-2541

10. Swee W, Dake MD. Endovascular management of thoracic dissections. Circulation 2008;117(11):1460-1473

11. Fattori R, Tsai T, Myrmel T, et al. Complicated acute type B dissection: is surgery still the best option? A report for the International Registry of Acute Aortic Dissection (IRAD). J Am Coll Cardiol Intv 2008;1:395-402

12. Song JM, Kim SD, Kim JH, et al. Long-term predictors of descending aorta aneurysmal change in patients with aortic dissection. J Am Coll Cardiol 2007;50(8):799-804

13. Mehta RH, O'Gara PT, Bossone E, et al; International Registry of Acute Aortic Dissection (IRAD) Investigators. Acute type A aortic dissection in the elderly: clinical characteristics, management, and outcomes in the current era. J Am Coll Cardiol 2002;40(4):685-692 
14. Masuda Y, Yamada Z, Morooka N, Watanabe S, Inagaki Y. Prognosis of patients with medically treated aortic dissections. Circulation 1991;84(5, Suppl):III7-III13

15. Ahmad F, Cheshire N, Hamady M. Acute aortic syndrome: pathology and therapeutic strategies. Postgrad Med J 2006; 82(967):305-312

16. Vilacosta I, San Román JA, Ferreirós J, et al. Natural history and serial morphology of aortic intramural hematoma: a novel variant of aortic dissection. Am Heart J 1997;134(3):495-507

17. Lissin LW, Vagelos R. Acute aortic syndrome: a case presentation and review of the literature. Vasc Med 2002; 7(4):281-287

18. Evangelista A, Mukherjee D, Mehta RH, et al; International Registry of Aortic Dissection (IRAD) Investigators. Acute intramural hematoma of the aorta: a mystery in evolution. Circulation 2005;111(8):1063-1070

19. Kaji S, Nishigami K, Akasaka $T$, et al. Prediction of progression or regression of type A aortic intramural hematoma by computed tomography. Circulation 1999; 100(19, Suppl):II281-II286

20. Schoder M, Grabenwöger $M$, Hölzenbein $T$, et al. Endovascular stent-graft repair of complicated penetrating atherosclerotic ulcers of the descending thoracic aorta. J Vasc Surg 2002;36(4):720-726

21. Sundt TM. Intramural hematoma and penetrating atherosclerotic ulcer of the aorta. Ann Thorac Surg 2007;83(2): S835-S841; discussion S846-S850

22. Eggebrecht H, Plicht B, Kahlert P, Erbel R. Intramural hematoma and penetrating ulcers: indications to endovascular treatment. Eur J Vasc Endovasc Surg 2009;38(6):659-665

23. Stanson AW, Kazmier FJ, Hollier LH, et al. Penetrating atherosclerotic ulcers of the thoracic aorta: natural history and clinicopathologic correlations. Ann Vasc Surg 1986;1(1):15-23

24. von Kodolitsch Y, Csösz SK, Koschyk DH, et al. Intramural hematoma of the aorta: predictors of progression to dissection and rupture. Circulation 2003;107(8):1158-1163

25. Macura KJ, Corl FM, Fishman EK, Bluemke DA. Pathogenesis in acute aortic syndromes: aortic dissection, intramural hematoma, and penetrating atherosclerotic aortic ulcer. AJR Am J Roentgenol 2003;181(2):309-316

26. Nienaber CA, Sievers HH. Intramural hematoma in acute aortic syndrome: more than one variant of dissection? Circulation 2002;106(3):284-285

27. Coady MA, Rizzo JA, Elefteriades JA. Pathologic variants of thoracic aortic dissections: penetrating atherosclerotic ulcers and intramural haematomas. Cardiol Clin North Am 1999; 113:603-604

28. Hussain S, Glover JL, Bree R, Bendick PJ. Penetrating atherosclerotic ulcers of the thoracic aorta. J Vasc Surg 1989; 9(5):710-717

29. Cho KR, Stanson AW, Potter DD, Cherry KJ, Schaff HV, Sundt TM III. Penetrating atherosclerotic ulcer of the descending thoracic aorta and arch. J Thorac Cardiovasc Surg 2004;127(5):1393-1399; discussion 1399-1401

30. Harris JA, Bis KG, Glover JL, Bendick PJ, Shetty A, Brown OW. Penetrating atherosclerotic ulcers of the aorta. J Vasc Surg 1994;19(1):90-98; discussion 98-99

31. Tisnado J, Cho SR, Beachley MC, Vines FS. Ulcerlike projections: a precursor angiographic sign to thoracic aortic dissection. AJR Am J Roentgenol 1980;135(4):719-722

32. Hayashi H, Matsuoka Y, Sakamoto I, et al. Penetrating atherosclerotic ulcer of the aorta: imaging features and disease concept. Radiographics 2000;20(4):995-1005
33. Wheat MW Jr, Palmer RF, Bartley TD, Seelman RC. Treatment of dissecting aneurysms of the aorta without surgery. J Thorac Cardiovasc Surg 1965;50:364-373

34. Wheat MW Jr. Current status of medical therapy of acute dissecting aneurysms of the aorta. World J Surg 1980; 4(5):563-569

35. Genoni M, Paul M, Jenni R, Graves K, Seifert B, Turina M. Chronic beta-blocker therapy improves outcome and reduces treatment costs in chronic type B aortic dissection. Eur J Cardiothorac Surg 2001;19(5):606-610

36. Kodama K, Nishigami K, Sakamoto T, et al. Tight heart rate control reduces secondary adverse events in patients with type B acute aortic dissection. Circulation 2008;118(14, Suppl): S167-S170

37. Takeshita S, Sakamoto S, Kitada S, Akutsu K, Hashimoto $\mathrm{H}$. Angiotensin-converting enzyme inhibitors reduce longterm aortic events in patients with acute type B aortic dissection. Circ J 2008;72(11):1758-1761

38. Tang DG, Dake MD. TEVAR for acute uncomplicated aortic dissection: immediate repair versus medical therapy. Semin Vasc Surg 2009;22(3):145-151

39. Doroghazi RM, Slater EE, DeSanctis RW, Buckley MJ, Austen WG, Rosenthal S. Long-term survival of patients with treated aortic dissection. J Am Coll Cardiol 1984; 3(4):1026-1034

40. Crawford ES, Svensson LG, Coselli JS, Safi HJ, Hess KR. Aortic dissection and dissecting aortic aneurysms. Ann Surg 1988;208(3):254-273

41. Daily PO, Trueblood HW, Stinson EB, Wuerflein RD, Shumway NE. Management of acute aortic dissections. Ann Thorac Surg 1970;10(3):237-247

42. Uchida N, Ishihara H, Shibamura H, Kyo Y, Ozawa M. Midterm results of extensive primary repair of the thoracic aorta by means of total arch replacement with open stent graft placement for an acute type A aortic dissection. J Thorac Cardiovasc Surg 2006;131(4):862-867

43. Svensson LG, Kouchoukos NT, Miller DC, et al; Society of Thoracic Surgeons Endovascular Surgery Task Force. Expert consensus document on the treatment of descending thoracic aortic disease using endovascular stent-grafts. Ann Thorac Surg 2008;85(1, Suppl):S1-S41

44. Deeb GM, Williams DM, Bolling SF, et al. Surgical delay for acute type A dissection with malperfusion. Ann Thorac Surg 1997;64(6):1669-1675; discussion 1675-1677

45. Patel HJ, Williams DM, Dasika NL, Suzuki Y, Deeb GM. Operative delay for peripheral malperfusion syndrome in acute type A aortic dissection: a long-term analysis. J Thorac Cardiovasc Surg 2008;135(6):1288-1295; discussion 12951296

46. Zoli S, Etz CD, Roder F, et al. Long-term survival after open repair of chronic distal aortic dissection. Ann Thorac Surg 2010;89(5):1458-1466

47. Vedantham S, Picus D, Sanchez LA, et al. Percutaneous management of ischemic complications in patients with type- $\mathrm{B}$ aortic dissection. J Vasc Interv Radiol 2003;14(2 Pt 1): 181-194

48. Ahmad F, Cheshire N, Hamady M. Acute aortic syndrome: pathology and therapeutic strategies. Postgrad Med J 2006; 82(967):305-312

49. Baikoussis NG, Apostolakis EE, Siminelakis SN, Papadopoulos GS, Goudevenos J. Intramural haematoma of the thoracic aorta: who's to be alerted the cardiologist or the cardiac surgeon? J Cardiothorac Surg 2009;4:54-60 
50. Di Eusanio M, Russo V, Buttazzi K, Lovato L, Di Bartolomeo R, Fattori R. Endovascular approach for acute aortic syndrome. J Cardiovasc Surg (Torino) 2010;51(3): 305-312

51. Tittle SL, Lynch RJ, Cole PE, et al. Midterm follow-up of penetrating ulcer and intramural hematoma of the aorta. J Thorac Cardiovasc Surg 2002;123(6):1051-1059

52. DiMusto PD, Williams DM, Patel HJ, Trimarchi S, Eliason JL, Upchurch GR Jr. Endovascular management of type B aortic dissections. J Vasc Surg 2010;52(4, Suppl):26S-36S

53. Williams DM, Lee DY, Hamilton BH, et al. The dissected aorta: part III. Anatomy and radiologic diagnosis of branchvessel compromise. Radiology 1997;203(1):37-44

54. Nienaber CA, Rousseau H, Eggebrecht H, et al; INSTEAD Trial. Randomized comparison of strategies for type B aortic dissection: the INvestigation of STEnt Grafts in Aortic Dissection (INSTEAD) trial. Circulation 2009;120(25): 2519-2528

55. Verhoye JP, Miller DC, Sze D, Dake MD, Mitchell RS. Complicated acute type B aortic dissection: midterm results of emergency endovascular stent-grafting. J Thorac Cardiovasc Surg 2008;136(2):424-430

56. Guangqi C, Xiaoxi L, Wei C, et al. Endovascular repair of Stanford type B aortic dissection: early and mid-term outcomes of 121 cases. Eur J Vasc Endovasc Surg 2009; 38(4):422-426

57. Nienaber CA, Rousseau H, Eggebrecht H, et al; INSTEAD Trial. Randomized comparison of strategies for type B aortic dissection: the INvestigation of STEnt Grafts in Aortic
Dissection (INSTEAD) trial. Circulation 2009;120(25): 2519-2528

58. Bortone AS, Schena S, D'Agostino D, et al. Immediate versus delayed endovascular treatment of post-traumatic aortic pseudoaneurysms and type B dissections: retrospective analysis and premises to the upcoming European trial. Circulation 2002;106(12, Suppl 1):I234-I240

59. Parker JD, Golledge J. Outcome of endovascular treatment of acute type B aortic dissection. Ann Thorac Surg 2008;86(5): 1707-1712

60. W.L. Gore \& Associates. A European Study of Medical Management Versus TAG Device and Medical Management for Acute Uncomplicated Type B Dissection (ADSORB). ClinicalTrials.gov. March 22, 2010Available at:http:// clincialtrials.gov/ct2/show/NCT00742274.

61. Monnin-Bares V, Thony F, Rodiere M, et al. Endovascular stent-graft management of aortic intramural hematomas. J Vasc Interv Radiol 2009;20(6):713-721

62. Grimm M, Loewe C, Gottardi R, et al. Novel insights into the mechanisms and treatment of intramural hematoma affecting the entire thoracic aorta. Ann Thorac Surg 2008; 86(2):453-456

63. Botta L, Buttazzi K, Russo V, et al. Endovascular repair for penetrating atherosclerotic ulcers of the descending thoracic aorta: early and mid-term results. Ann Thorac Surg 2008; 85(3):987-992

64. Brinster DR. Endovascular repair of the descending thoracic aorta for penetrating atherosclerotic ulcer disease. J Card Surg 2009;24(2):203-208 